OPEN ACCESS

Edited by:

Ahsan H. Khandoker,

Khalifa University, UAE

Reviewed by:

Mathias Baumert,

University of Adelaide, Australia

Edward Joseph Vigmond,

University of Bordeaux 1, France

Helmut Ahammer,

Medical University of Graz, Austria

${ }^{*}$ Correspondence:

Oliver J. Britton

oliver.britton@cs.ox.ac.uk

Specialty section:

This article was submitted to

Computational Physiology and

Medicine,

a section of the journal

Frontiers in Physiology

Received: 27 January 2017 Accepted: 18 April 2017

Published: 05 May 2017

Citation:

Britton OJ, Bueno-Orovio A, Virág L, Varró $A$ and Rodriguez B (2017) The Electrogenic $\mathrm{Na}^{+} / \mathrm{K}^{+}$Pump Is a Key

Determinant of Repolarization Abnormality Susceptibility in Human

Ventricular Cardiomyocytes: A Population-Based Simulation Study.

Front. Physiol. 8:278

doi: 10.3389/fphys.2017.00278

\section{The Electrogenic $\mathrm{Na}^{+} / \mathrm{K}^{+}$Pump Is a Key Determinant of Repolarization Abnormality Susceptibility in Human Ventricular Cardiomyocytes: A Population-Based Simulation Study}

\author{
Oliver J. Britton ${ }^{1 *}$, Alfonso Bueno-Orovio ${ }^{1}$, László Virág ${ }^{2}$, András Varró ${ }^{2}$ and \\ Blanca Rodriguez ${ }^{1}$ \\ ${ }^{1}$ Department of Computer Science, University of Oxford, Oxford, UK, ${ }^{2}$ Department of Pharmacology and Pharmacotherapy, \\ Faculty of Medicine, University of Szeged, Szeged, Hungary
}

Background: Cellular repolarization abnormalities occur unpredictably due to disease and drug effects, and can occur even in cardiomyocytes that exhibit normal action potentials (AP) under control conditions. Variability in ion channel densities may explain differences in this susceptibility to repolarization abnormalities. Here, we quantify the importance of key ionic mechanisms determining repolarization abnormalities following ionic block in human cardiomyocytes yielding normal APs under control conditions.

Methods and Results: Sixty two AP recordings from non-diseased human heart preparations were used to construct a population of human ventricular models with normal APs and a wide range of ion channel densities. Multichannel ionic block was applied to investigate susceptibility to repolarization abnormalities. $I_{\mathrm{Kr}}$ block was necessary for the development of repolarization abnormalities. Models that developed repolarization abnormalities over the widest range of blocks possessed low $\mathrm{Na}^{+} / \mathrm{K}^{+}$ pump conductance below 50\% of baseline, and $\mathrm{I}_{\mathrm{CaL}}$ conductance above $70 \%$ of baseline. Furthermore, $I_{\mathrm{NaK}}$ made the second largest contribution to repolarizing current in control simulations and the largest contribution under $75 \% \mathrm{I}_{\mathrm{Kr}}$ block. Reversing intracellular $\mathrm{Na}^{+}$overload caused by reduced $I_{\mathrm{NaK}}$ was not sufficient to prevent abnormalities in models with low $\mathrm{Na}^{+} / \mathrm{K}^{+}$pump conductance, while returning $\mathrm{Na}^{+} / \mathrm{K}^{+}$ pump conductance to normal substantially reduced abnormality occurrence, indicating $I_{\text {NaK }}$ is an important repolarization current.

Conclusions: $I_{\mathrm{NaK}}$ is an important determinant of repolarization abnormality susceptibility in human ventricular cardiomyocytes, through its contribution to repolarization current rather than homeostasis. While we found $I_{\mathrm{kr}}$ block to be necessary for repolarization abnormalities to occur, $I_{\mathrm{NaK}}$ decrease, as in disease, may amplify the pro-arrhythmic risk of drug-induced $\mathrm{I}_{\mathrm{Kr}}$ block in humans.

Keywords: human, repolarization, cardiac electrophysiology modeling, variability, sodium-potassium pump, $\mathrm{Na}^{+} / \mathrm{K}^{+}$pump 


\section{INTRODUCTION}

Recent evidence points toward possible large variations in ion channel densities in cardiac cells, that are modulated by environmental and intrinsic factors including: circadian rhythms (Jeyaraj et al., 2012); exposure to hormones (Odening and Koren, 2014); to drugs (Xiao et al., 2008); to sustained change in pacing rate (Qi et al., 2008); to arrhythmias (Nattel et al., 2007); and to disease (Nass et al., 2008; Michael et al., 2009). Regulation of mRNA expression (Nattel et al., 2010) and further regulation of mRNA by miRNA (Kim, 2013) are two mechanisms by which cardiomyocytes can remodel their complement of ion channels in response to dynamic changes in cellular external conditions. Therefore, cells have the ability to adapt to environmental factors by modulating their ion channel densities while still maintaining their physiological function, represented in cardiomyocytes by the action potential (AP).

Aggressive external stimuli such as drugs or disease can sometimes challenge the stable behavior of cardiomyocytes leading to unexpected and potentially lethal abnormalities, even in tissue exhibiting apparently healthy behavior under normal conditions. In the case of the heart, its normal function can be disrupted by the presence of repolarization abnormalities, including early afterdepolarizations (EADs) and repolarization failure, which are rare and unpredictable proarrhythmic side-effects of disease and drug application. A wide range of ionic mechanisms have been identified as contributors to repolarization abnormalities, mostly through animal studies. Ionic mechanisms implicated include reduced repolarization reserve (Roden, 1998); L-type $\mathrm{Ca}^{2+}$ current $\left(\mathrm{I}_{\mathrm{CaL}}\right)$ reactivation (January and Riddle, 1989); and intracellular $\mathrm{Ca}^{2+}$ overload, driven by either external changes, or by modulation of the $\mathrm{Na}^{+} / \mathrm{Ca}^{2+}$ exchanger $\left(\mathrm{I}_{\mathrm{NCX}}\right)$ or $\mathrm{Na}^{+} / \mathrm{K}^{+}$ pump ( $\mathrm{I}_{\mathrm{NaK}}$ ) currents (Weiss et al., 2010; Despa and Bers, 2013; Bueno-Orovio et al., 2014; Shattock et al., 2015). Whereas animal studies have shown the importance of these individual mechanisms as contributors to repolarization abnormality generation under specific conditions, a quantitative understanding of the interactions and relative importance of these mechanisms in human ventricular cardiomyocytes affected by ionic current block is still missing.

In this study, we aim to quantitatively investigate the mechanisms underlying repolarization abnormalities in human cardiomyocytes, with a wide range of ionic profiles to consider variability in ionic properties. We specifically focus on investigating human cardiomyocytes yielding a normal AP under control conditions, using a population of human ventricular cardiomyocyte models (Britton et al., 2013) calibrated with experimental electrophysiological recordings.

\section{METHODS}

\section{Population of Human Ventricular Cell Models}

The O'Hara-Virag-Varro-Rudy (ORd) model (O'Hara et al., 2011) of the human ventricular cardiomyocyte was used as the baseline model for our investigations, as it is one of the most recent, widely used and extensively tested models of the human ventricular cardiomyocyte, and is particularly well-suited for studying human ventricular repolarization, as key currents involved in repolarization and EAD formation (including $\mathrm{I}_{\mathrm{Kr}}$, $\mathrm{I}_{\mathrm{Ks}}, \mathrm{I}_{\mathrm{K} 1}$, and $\mathrm{I}_{\mathrm{CaL}}$ ) are parameterized using data exclusively from undiseased human ventricular cardiomyocytes.

We constructed a population of 10,000 human models, each based on the ORd formulation but with differences in the conductance values for 9 key sarcolemmal currents, based on our assumptions that ionic conductances are highly variable, due to both intracellular factors and responses to external stimuli. The conductances varied were those with the most influence on the human ventricular AP: $\mathrm{I}_{\mathrm{Na}}$ (fast $\mathrm{Na}^{+}$current); $\mathrm{I}_{\mathrm{NaL}}$ (late $\mathrm{Na}^{+}$current); $\mathrm{I}_{\text {CaL }}$ (L-type Ca ${ }^{2+}$ current); $\mathrm{I}_{\text {to }}$ (transient outward $\mathrm{K}^{+}$current); $\mathrm{I}_{\mathrm{Kr}}$ (rapid delayed rectifier $\mathrm{K}^{+}$current); $\mathrm{I}_{\mathrm{Ks}}$ (slow delayed rectifier $\mathrm{K}^{+}$current); $\mathrm{I}_{\mathrm{K} 1}$ (inward rectifier $\mathrm{K}^{+}$current); $\mathrm{I}_{\mathrm{NCX}} ;\left(\mathrm{Na}^{+} / \mathrm{Ca}^{2+}\right.$ exchanger current) and $\mathrm{I}_{\mathrm{NaK}}\left(\mathrm{Na}^{+} / \mathrm{K}^{+}\right.$pump current). Latin hypercube sampling (McKay et al., 1979) was used to sample sets of conductances uniformly while co-varying all conductances.

As in Britton et al. (2013) we selected a wide sampling range of $0-2$ times the baseline value of each conductance to allow models with a wide variety of underlying ionic current configurations, including both increased and reduced channel densities, to be evaluated and potentially accepted into the population if they passed the filtering process. This range is necessarily an assumption as this range cannot be measured in vivo, and voltage clamp measurements of ionic current conductances in isolated cells are affected by the isolation process (Borg and Terracio, 1990). Using a lower sampling limit of 0 also allows the possibility of models with very low, potentially pathological values for some conductances, providing the resulting model can still produce a normal control AP. This choice of limit is intentional, to allow the investigation of abnormal ionic profiles that produce normal APs in control conditions but may have increased susceptibility to repolarization abnormalities under channel block. All conductance values in this study are given as scaling factors of the baseline ORd model's conductances.

\section{Experimental Filtering to Select Normal APs in Control Conditions}

Experimental recordings of human AP were obtained as described in O'Hara et al. (2011) from human right ventricular trabeculae and papillary tissue preparations of $<2 \mathrm{~cm}$ in diameter, dissected from non-failing human hearts, perfused and paced at $1 \mathrm{~Hz}$. Small tissue preparations, rather than isolated cells, were used in this study to avoid the damage to ion channels caused by the isolation process. AP recordings were acquired from these preparations using conventional microelectrode techniques from 62 experiments performed using tissue preparations from 37 hearts (16 females, 21 males, mean age $43 \pm 13$ years). The recordings used in this study were obtained from a database of recordings from multiple previous studies, all conducted by the same laboratory, which we then further analyzed to calculate biomarker values and experimental ranges. Further details of the preparation process and recording equipment are available in Jost et al. (2005). The preparations used in this study were obtained from hearts donated for research in compliance with the Declaration of Helsinki and approved by 
the Scientific and Research Ethical Committee of the Medical Scientific Board of the Hungarian Ministry of Health (ETTTUKEB), under ethical approval No 4991-0/2010-1018EKU (339/PI/010).

The data were analyzed to obtain the experimental ranges of seven biomarkers, which are shown in Figure 1. For each biomarker, experimental ranges were calculated from the minimum and maximum values observed in the data set at $1 \mathrm{~Hz}$ control conditions pacing, after excluding three clear outliers, one due to an exceptionally long APD90 (543 ms, data set mean = $293 \pm 66 \mathrm{~ms}$ ) and two due to exceptionally long times to peak (26 and $38 \mathrm{~ms}$, data set mean $=6.7 \pm 5.4 \mathrm{~ms}$ ). The calculated biomarker ranges are displayed in Table S2. Biomarker values were generated for each experiment by calculating the value of each biomarker in the final recorded AP trace of the control portion of each experiment. These experimental ranges were then used to constrain the population of models to only those models that produced normal AP behavior under $1 \mathrm{~Hz}$ pacing in control conditions. We refrained from using any additional constraints on the population, to create a population of models with normal APs under normal pacing conditions, but with a wide range of underlying conductances, that we hypothesized would lead to a diverse range of susceptibilities to drug-induced repolarization abnormalities. Performing this filtering led to a total of 568 models of the initial 10,000 being accepted as having normal human ventricular APs; their parameter values are provided in Table S3 in the Supplementary Material.

\section{Detection and Classification of Repolarization Abnormalities}

Simulations were carried out with the 568 models to investigate the occurrence of repolarization abnormalities following block of $\mathrm{I}_{\mathrm{Kr}}, \mathrm{I}_{\mathrm{Ks}}, \mathrm{I}_{\mathrm{K} 1}$, and $\mathrm{I}_{\mathrm{CaL}}$, often considered the key currents that contribute during repolarization (January and Riddle, 1989; Weiss et al., 2010; Varro and Baczko, 2011). We simulated block of all possible two-current pairs of these four currents (6 combinations) and for each pair simulated the 16 possible combinations of 4 block strengths (a $25,50,75$, or $90 \%$ reduction in the appropriate conductance), for a total of 96 simulations performed on each of the 568 models. These simulations represent possible effects of non-selective blockers such as verapamil and dronedarone, both of which block $\mathrm{I}_{\mathrm{Kr}}$ and $\mathrm{I}_{\mathrm{CaL}}$ (Zhang et al., 1999; Varró et al., 2001), or combinations of selective blockers, e.g., dofetilide and HMR-1556 (Jost et al., 2013). We performed a systematic analysis of block levels, rather than matching specific compounds at set concentrations, to analyze the effects of a wide range of possible block scenarios, and because of the large uncertainties in IC50 values measured for concentration-dependent channel block (Polak et al., 2009).

Repolarization abnormalities (Figure 2) were detected by analyzing the voltage-time gradient of the final two pacing cycles of a simulation. A positive gradient greater than $0.02 \mathrm{mV} / \mathrm{ms}$ more than $100 \mathrm{~ms}$ after the initial upstroke was used as an automatic detector of afterdepolarizations. We used a $100 \mathrm{~ms}$ delay to avoid models with either delayed initial upstroke or a spike and dome configuration from being misclassified as displaying afterdepolarizations.

For each drug block simulation we recorded which models developed repolarization abnormalities. Each model in the population was then categorized by the number of different channel block simulations in which they developed repolarization abnormalities. Models which did not develop repolarization abnormalities in any of the simulations were classified as not susceptible (NS), models which developed repolarization abnormalities in 1-9 of the simulations were classified as moderately susceptible (MS) and models which

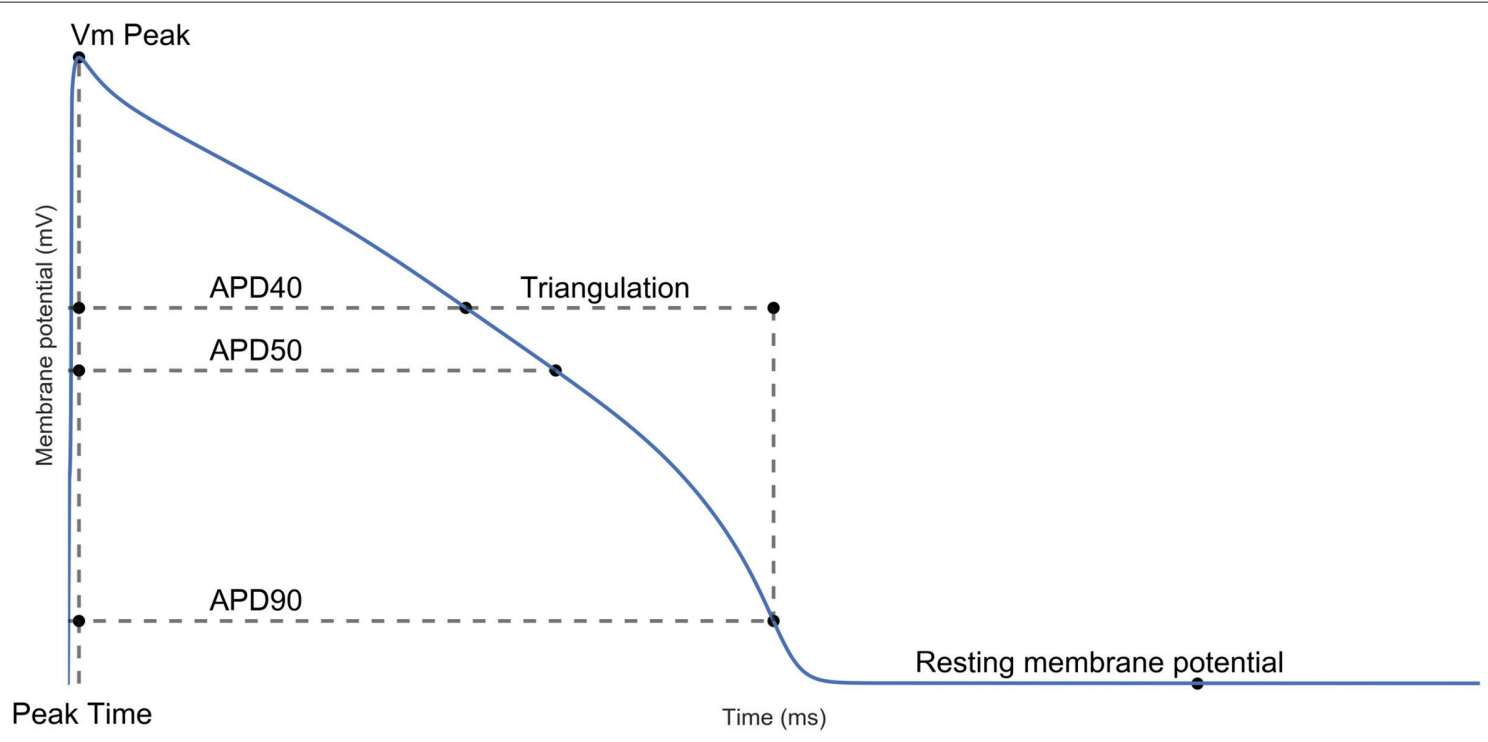

FIGURE 1 | Action potential biomarkers. Peak membrane potential $\left(V_{m}\right.$ Peak); time of peak membrane potential ( $V_{m}$ Time); AP duration (APD) at 40/50/90\% repolarization; triangulation and resting membrane potential (RMP). Each biomarker was calculated as defined in the Supplementary Material. 


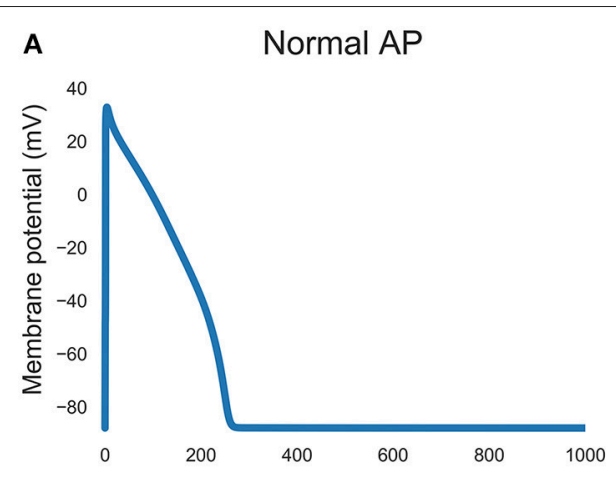

B $\quad$ EAD

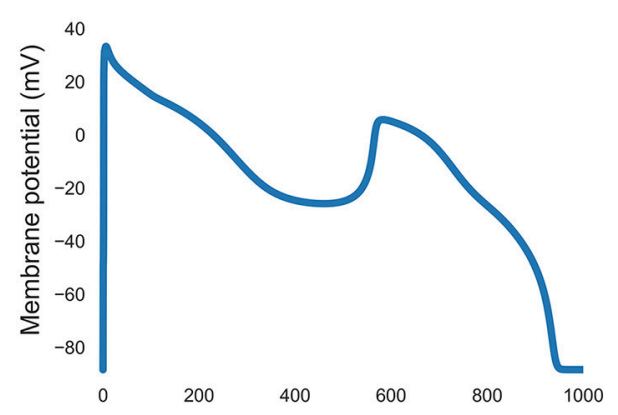

c Repolarization failure

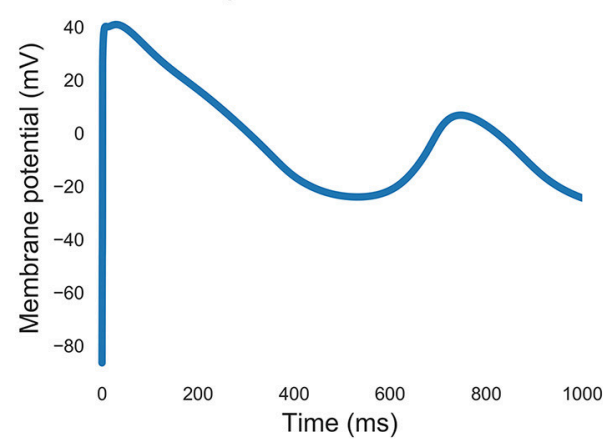

FIGURE 2 | Examples of action potential traces. (A) Normal repolarization. (B) An early afterdepolarization. (C) Repolarization failure.

developed repolarization abnormalities in 10 or more of the simulations were classified as highly susceptible (HS). The threshold separating MS and HS models was selected as it marked a particularly large drop in the number of models displaying repolarization abnormalities in $\mathrm{N}$ or more simulations occurred between $N=8$ and $N=10$ (Figure S1).

\section{Statistical Methods}

We used the Mann-Whitney U-test to determine statistical differences between groups of biomarker values, as it is nonparametric and therefore did not require any assumption of the underlying distributions of biomarker values. Partial correlation coefficients were used to determine correlations between conductances, while controlling for the effects of all other co-varying conductances. Multiple comparisons were corrected for with Bonferroni correction.

A logistic regression model was developed to determine whether models that were highly susceptible to repolarization abnormalities could be classified based on their biomarker values alone. The z-scored values of the seven biomarkers used in this study, obtained from each model in the population, were used as features to train the logistic regression model, which was then used classify models in the test sets as either belonging to the HS category, or not. This classification was then compared to the true categorization. Ten-fold cross validation was used to generate multiple training and testing data sets.

Additional details on simulation protocols and the choice of model used in this study can be found in the Supplementary Material.

\section{RESULTS}

\section{Properties of the Population of Human Ventricular Cell Models}

Figure $3 \mathbf{A}$ shows voltage traces from human models in the population spanning the range seen in experiments, and the baseline ORd model, which has a slightly higher peak membrane potential $(45.6 \mathrm{mV})$ than the highest values seen in our data (39.6 $\mathrm{mV}$ ), but otherwise would be a viable model in our population. Figure 3B shows that variability in conductances can reproduce the variability in the experimental biomarkers. One possible exception is RMP, which is highly dependent on the extracellular $\mathrm{K}^{+}$concentration, considered constant in our simulations.

Figures 3C-J shows that most of the conductances span the full sampled range ( $0-2$ times the ORd model's baseline value for that conductance), highlighting the robustness of the human AP against conductances variations. However, $\mathrm{G}_{\mathrm{Na}}, \mathrm{G}_{\mathrm{CaL}}$, and $\mathrm{G}_{\mathrm{Kr}}$ are constrained by the calibration (Figures $3 \mathrm{E}, \mathrm{G}$ ). $\mathrm{G}_{\mathrm{Na}}$ is confined to the smallest range, $92 \%$ of the models in the population have $G_{\mathrm{Na}}$ values clustered between 0.2 and $1 . \mathrm{G}_{\mathrm{CaL}}$ values are densely distributed between 0 and 1 ( $81 \%$ of the population), so that few models have high $\mathrm{G}_{\mathrm{CaL}}$ values (e.g., Figure 3E). Low values of $\mathrm{G}_{\mathrm{Kr}}$ (below 0.13 ) are not present in the population (e.g., Figure $3 G$ ), suggesting that a minimum amount of $\mathrm{I}_{\mathrm{Kr}}$ is necessary in the cell for successful repolarization under normal conditions, but the distribution of $G_{K r}$ values spans the rest of the sampled range. All possible pairings of ionic conductances within the population of models are shown in Figure S2. Results demonstrate that a normal AP can be generated by a wide variety of different balances of ionic currents, although these balances may have very different responses to changing conditions.

To test whether the balance of repolarizing currents in the population of models resulted in a realistic range of APD prolongation values under $\mathrm{I}_{\mathrm{Kr}}$ block, we compared the $\mathrm{APD}_{90}$ prolongation caused by application of $0.05 \mu \mathrm{M}$ dofetilide (a selective $\mathrm{I}_{\mathrm{Kr}}$ blocker) to the prolongation caused by equivalent $\mathrm{I}_{\mathrm{Kr}}$ block on the population of models (Figure 4). Dofetilide was modeled as a single-pore $I_{\mathrm{Kr}}$ inhibitor with a Hill coefficient of 1.2 and an IC50 of $0.03 \mu \mathrm{M}$ based on data from Kramer et al. 


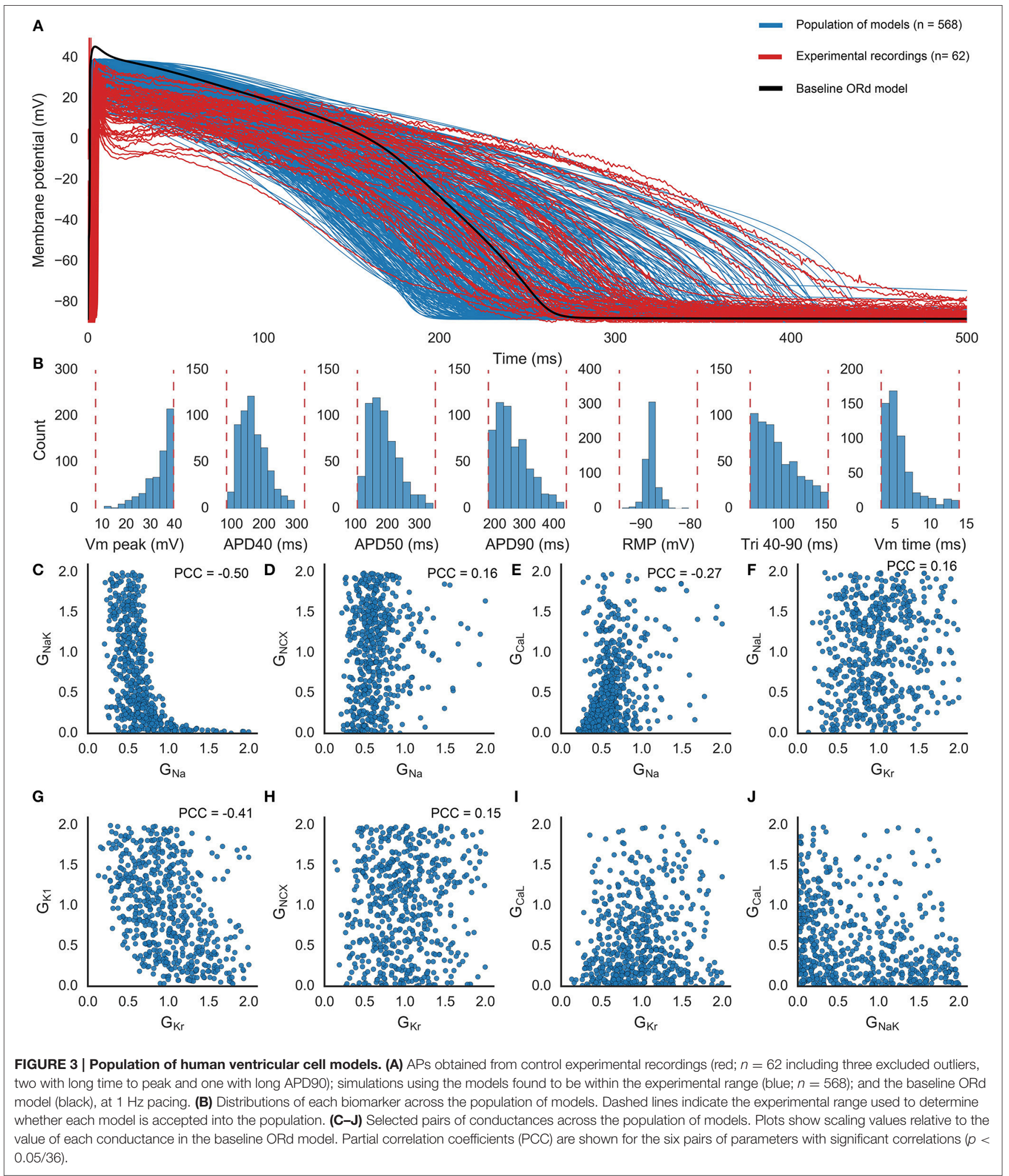

(2013), giving a resulting $\mathrm{I}_{\mathrm{Kr}}$ block of $65 \%$. The distributions of APD prolongation overlap between experiment and the population. This provides confidence that a realistic balance of
$\mathrm{I}_{\mathrm{Kr}}$ and other repolarizing currents is captured by the population. There are some outliers in the population that are not seen in experiments, and 7/568 models were excluded from the figure 


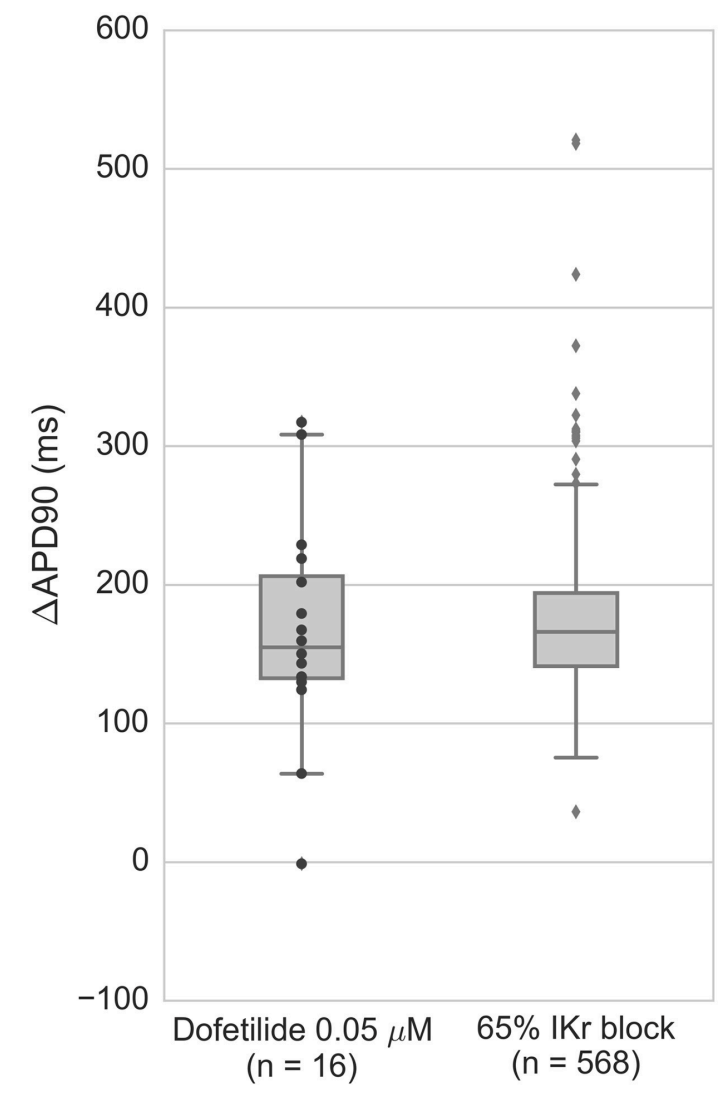

FIGURE 4 | APD prolongation of ventricular preparations under 0.05 $\mu \mathrm{M}$ dofetilide $(n=16)$ compared to population of models under $65 \%$ $\mathrm{I}_{\mathrm{Kr}}$ block, corresponding to the effects of $0.5 \mu \mathrm{M}$ dofetilide using IC50 and Hill coefficient determined by Kramer et al. (2013). Models displaying repolarization abnormalities (7/568 models) were excluded from the figure. Black dots are experimental data points, gray dots are outliers ( $>1.5$ times interquartile range from the nearest inner quartile).

due to developing repolarization abnormalities. This can be explained by the wider range of conductances explored in the population of models compared to the limited set of experimental data in non-diseased hearts.

\section{$\mathrm{I}_{\mathrm{Kr}}$ Block Induces Repolarization Abnormalities, Augmented by $I_{\mathrm{Ks}}$ and $I_{\mathrm{K} 1}$ Block, and Opposed by I CaL Block}

To investigate our hypothesis that the different conductance profiles in our population would result in different levels of susceptibility to repolarization abnormalities, multiple channel block simulations blocking pairs of the currents $\mathrm{I}_{\mathrm{Kr}}, \mathrm{I}_{\mathrm{Ks}}$, $\mathrm{I}_{\mathrm{K} 1}$, and $\mathrm{I}_{\mathrm{CaL}}$ at a range of block strengths, were conducted as described in Methods. The percentage of models in the population that generated abnormalities in each simulation, are shown in Figures 5A-C for the combinations of currents where abnormalities were detected in at least one simulation. Out of the 96 multichannel block simulations, 29 simulations caused at least one model to develop abnormalities. $\mathrm{I}_{\mathrm{Kr}}$ block was the primary cause of repolarization abnormalities. No abnormalities were observed in any simulation where $\mathrm{I}_{\mathrm{Kr}}$ was blocked by less than $50 \%$, even though models with very low values of $\mathrm{G}_{\mathrm{Kr}}$ were considered in the population. Block of either $\mathrm{I}_{\mathrm{K} 1}$ or $\mathrm{I}_{\mathrm{Ks}}$ acted to augment $\mathrm{I}_{\mathrm{Kr}}$ block and increased the number of models that produced abnormalities (Figures $\mathbf{5 A}, \mathbf{B}$ ), but were not sufficient to produce abnormalities without $\mathrm{I}_{\mathrm{Kr}}$ block. $\mathrm{I}_{\mathrm{CaL}}$ block attenuated the effects of $\mathrm{I}_{\mathrm{Kr}}$ block, reducing the number of abnormalities seen in the population (Figure 5C). At $75 \% \mathrm{I}_{\mathrm{Kr}}$ block, $50 \%$ block of $\mathrm{I}_{\mathrm{CaL}}$ was sufficient to abolish all repolarization abnormalities. For $90 \% \mathrm{I}_{\mathrm{Kr}}$ block, $75 \% \mathrm{I}_{\mathrm{CaL}}$ block was required to achieve the same effect. In both cases, even $25 \%$ block of $I_{C a L}$ was sufficient to substantially reduce the incidence of repolarization abnormalities in the population, from 4 to $1 \%$ of models for $75 \% \mathrm{I}_{\mathrm{Kr}}$ block, and from 18 to $10 \%$ for $90 \% \mathrm{I}_{\mathrm{Kr}}$ block. Overall, when the population was exposed to both $\mathrm{I}_{\mathrm{Kr}}$ and $\mathrm{I}_{\mathrm{CaL}}$ block, few models produced abnormalities. However, we found that the APD prolongation caused by $\mathrm{I}_{\mathrm{Kr}}$ block was only slightly reduced by $\mathrm{I}_{\mathrm{CaL}}$ block (Figure S3).

\section{Low $\mathrm{G}_{\mathrm{NaK}}$ and High $\mathrm{G}_{\mathrm{CaL}}$ Indicate Particular Susceptibility to Repolarization Abnormalities}

To analyze how susceptibility to repolarization abnormalities depended on underlying conductance and biomarker values, we classified each model as non-susceptible (NS), moderately susceptible (MS), or highly susceptible (HS) to repolarization abnormalities (see Methods). Out of 568 models, 380 models (67\%) were NS, 147 (26\%) were MS and 41 (7\%) were HS.

We investigated whether the susceptibility of models could be distinguished prior to current block by the control values of any of the seven biomarkers we used to calibrate the population. We found that the median control conditions biomarker values for all biomarkers except for $\mathrm{V}_{\mathrm{m}}$ Time were significantly different (Mann-Whitney U-test, $p<0.001$ ) between the subpopulation of HS models and the rest of the population (Figure 5D). To determine whether control biomarker values were sufficient to predict which models were highly susceptible to repolarization abnormalities, we constructed a logistic regression model using the biomarkers of the population as predictor variables, to estimate the probability of each parameter set belonging to either the HS or non-HS groups. Over 1,000 iterations of 10 -fold cross validation, the logistic regression model only achieved a $61 \%$ mean rate of correctly predicting HS models to be in the HS category. This low level of sensitivity suggests that the biomarkers used to calibrate the population are insufficient to predict model susceptibility prior to current block. This is likely due to the high level of overlap in biomarker distributions between the HS and the two other model classifications.

We then tested whether any of the nine conductances that were varied to create the population of models were significantly different between any of the three categories. Median $\mathrm{G}_{\mathrm{Na}}$, $\mathrm{G}_{\mathrm{CaL}}$, and $G_{N a K}$ values were significantly different between all three categories of model $\left(p<0.05 / 27\right.$, Figure 5E). $\mathrm{G}_{\mathrm{Na}}$ and $\mathrm{G}_{\mathrm{CaL}}$ were 


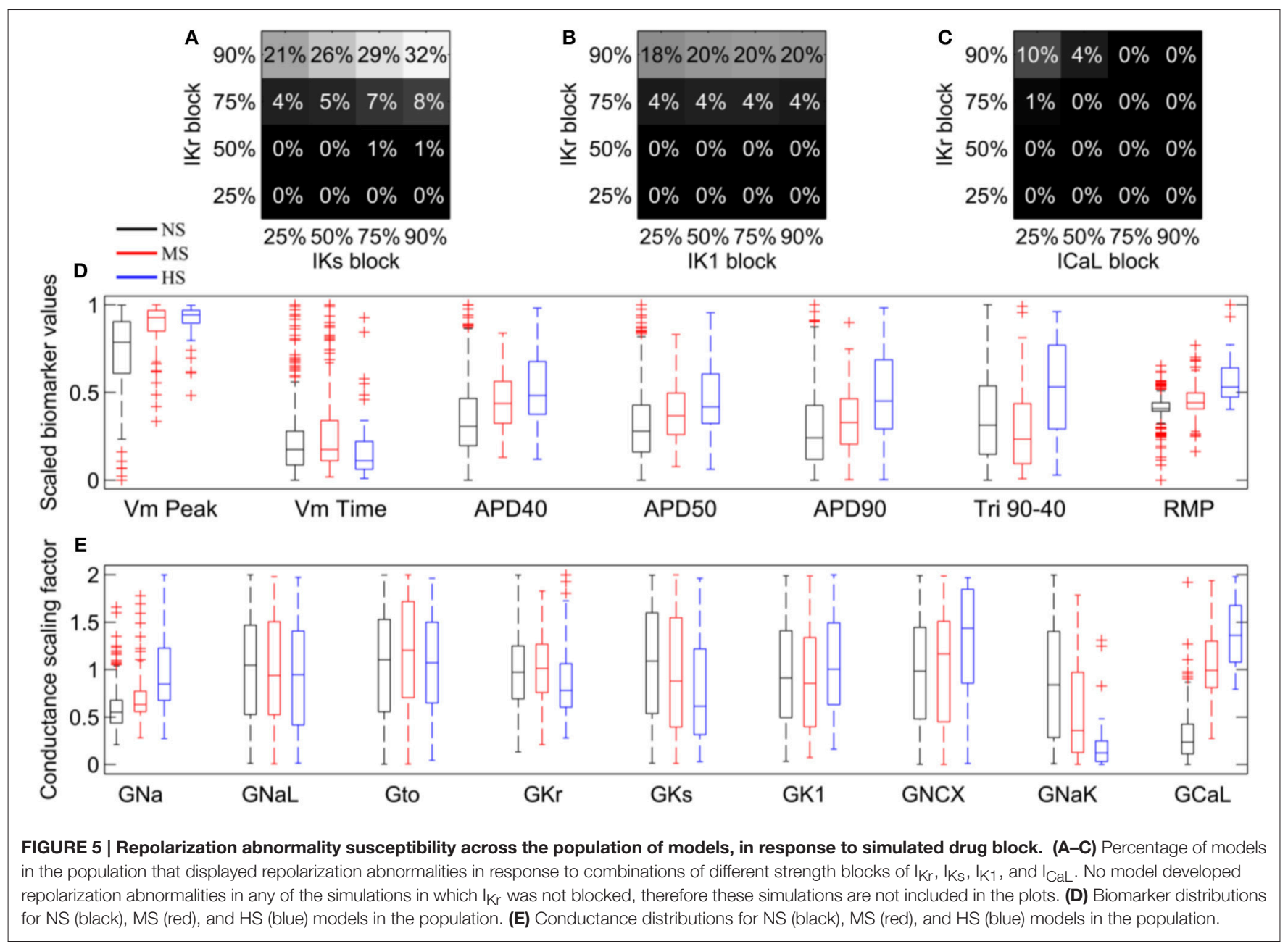

larger in the higher susceptibility (MS and HS) categories, while $\mathrm{G}_{\mathrm{NaK}}$ was smaller. $\mathrm{G}_{\mathrm{NCX}}$ was also significantly different between the NS and HS categories, but not between the MS category and either of the other categories. Additionally, the range of $\mathrm{G}_{\mathrm{NCX}}$ for all three categories spanned the full sampled range of the conductance, unlike $\mathrm{G}_{\mathrm{Na}}, \mathrm{G}_{\mathrm{CaL}}$, and $\mathrm{G}_{\mathrm{NaK}}$ (Figure $5 \mathrm{E}$ ). Therefore, we focused on $G_{\mathrm{Na}}, G_{\mathrm{CaL}}$, and $G_{\mathrm{NaK}}$ as potential contributors to repolarization abnormality susceptibility.

Using the models in the HS category, we investigated the relative importance of $\mathrm{I}_{\mathrm{Na}}, \mathrm{I}_{\mathrm{CaL}}$, and $\mathrm{I}_{\mathrm{NaK}}$, and repolarizing currents $\mathrm{I}_{\mathrm{Kr}}, \mathrm{I}_{\mathrm{Ks}}$ and $\mathrm{I}_{\mathrm{K} 1}$, during early and late periods of repolarization (we define early repolarization as from the AP peak to $40 \%$ repolarization, and late repolarization as from 40 to $90 \%$ repolarization). Figure 6 displays the average magnitudes of those six currents during each period of repolarization for the 41 HS models, under control conditions and 75\% $\mathrm{I}_{\mathrm{Kr}}$ block (data for NS and MS models are shown in Figure S4). Under control conditions $\mathrm{I}_{\mathrm{Kr}}$ was the largest repolarizing current (mean current density from $\mathrm{V}_{\mathrm{m}}$ Peak to $\mathrm{APD}_{90}: 0.49 \pm 0.21 \mathrm{~A} / \mathrm{F}$ ). Unexpectedly, $\mathrm{I}_{\mathrm{NaK}}$ was the second largest repolarizing current overall $(0.15$ $\pm 0.05 \mathrm{~A} / \mathrm{F})$, substantially larger than $\mathrm{I}_{\mathrm{Ks}}(0.04 \pm 0.03 \mathrm{~A} / \mathrm{F})$, although $\mathrm{I}_{\mathrm{K} 1}$ was larger than $\mathrm{I}_{\mathrm{NaK}}$ during late repolarization only
$\left(\mathrm{I}_{\mathrm{K} 1}: 0.18 \pm 0.07 \mathrm{~A} / \mathrm{F}, \mathrm{I}_{\mathrm{NaK}}: 0.12 \pm 0.04 \mathrm{~A} / \mathrm{F}\right)$. During $75 \% \mathrm{I}_{\mathrm{Kr}}$ block, $\mathrm{I}_{\mathrm{NaK}}$ became the largest repolarizing current $\left(\mathrm{I}_{\mathrm{NaK}}: 0.11\right.$ $\pm 0.04 \mathrm{~A} / \mathrm{F}, \mathrm{I}_{\mathrm{Kr}}$ under $75 \%$ block: $\left.0.03 \pm 0.02 \mathrm{~A} / \mathrm{F}\right) . \mathrm{I}_{\mathrm{CaL}}$ was a major contributor of inward current during early repolarization under both control conditions and $\mathrm{I}_{\mathrm{Kr}}$ block. During late repolarization the magnitude of $\mathrm{I}_{\mathrm{CaL}}$ under $75 \% \mathrm{I}_{\mathrm{Kr}}$ block was increased by over $200 \%$ compared to control conditions (control: $-0.05 \pm 0.03 \mathrm{~A} / \mathrm{F}, \mathrm{I}_{\mathrm{Kr}}$ block: $-0.16 \pm 0.01 \mathrm{~A} / \mathrm{F}$ ), which supports the importance of $\mathrm{I}_{\mathrm{CaL}}$ reactivation in the generation of repolarization abnormalities. $\mathrm{I}_{\mathrm{Na}}$ magnitude was not elevated under $\mathrm{I}_{\mathrm{Kr}}$ block compared to control conditions (control: -0.007 $\pm 0.005 \mathrm{~A} / \mathrm{F}, \mathrm{I}_{\mathrm{Kr}}$ block: $\left.-0.003 \pm 0.004 \mathrm{~A} / \mathrm{F}\right)$, suggesting it does not contribute to repolarization abnormality generation directly. However, we found that models with high $\mathrm{G}_{\mathrm{Na}}$ correlated with models with low $\mathrm{G}_{\mathrm{NaK}}$ (Figure 3C). Therefore, high $\mathrm{G}_{\mathrm{Na}}$ may be compensatory for the increased intracellular $\mathrm{Na}^{+}$in models with low $\mathrm{G}_{\mathrm{NaK}}$ (mean intracellular $\mathrm{Na}^{+}$was $16.4 \pm 6.4 \mathrm{mM}$ in HS models, compared with $8.9 \pm 3.9 \mathrm{mM}$ in the rest of the population), and the resulting decrease in inward $\mathrm{Na}^{+}$driving force.

Overall, we identified low $\mathrm{G}_{\mathrm{NaK}}$ and high $\mathrm{G}_{\mathrm{CaL}}$ as key factors that increased susceptibility to repolarization abnormalities 


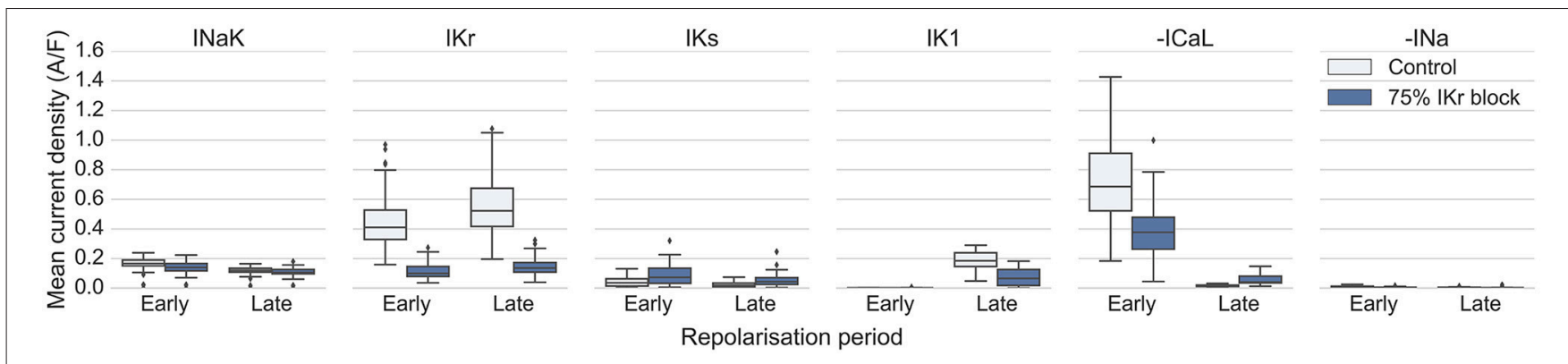

FIGURE 6 | Magnitude of $I_{\mathrm{Na}}, \mathrm{I}_{\mathrm{CaL}}, \mathrm{I}_{\mathrm{NaK}}, \mathrm{I}_{\mathrm{Kr}}, \mathrm{I}_{\mathrm{Ks}}$, and $\mathrm{I}_{\mathbf{K} 1}$ during repolarization for $\mathrm{HS}$ models in control conditions and under $75 \% \mathrm{I}_{\mathbf{K r}}$ block. Each current was averaged from the peak of the upstroke to APD40 (early) and from APD 40 to APD90 (late), for each model.

and distinguished highly susceptible models from the rest of the population, and found that $\mathrm{I}_{\mathrm{NaK}}$ makes a key contribution to repolarization current, particularly under $\mathrm{I}_{\mathrm{Kr}}$ block.

\section{Low $G_{\text {NaK }}$ Decreases Repolarization Reserve As Well As Increasing Intracellular $\mathrm{Na}^{+}$}

A large majority (38/41) of the HS models in the population had $\mathrm{G}_{\mathrm{NaK}}$ values of less than 0.5 times its value in the baseline ORd model, and values of $\mathrm{G}_{\mathrm{CaL}}$ greater than 0.78 times the baseline value (Figure 7A). Repolarization abnormality occurrence across the HS models under 75 and $90 \% \mathrm{I}_{\mathrm{Kr}}$ block was 51 and $95 \%$ of models respectively (Figure 7B). After increasing $\mathrm{G}_{\mathrm{NaK}}$ to the ORd model's baseline value (i.e., a scaling factor of 1.0) in each HS model, repolarization abnormality occurrence fell to 10 and $71 \%$ of models respectively. The reversion of an example HS model to a normal AP phenotype following increase of $\mathrm{G}_{\mathrm{NaK}}$ in this way is shown in Figures 7D-G.

We hypothesized that the importance of $\mathrm{G}_{\mathrm{NaK}}$ in determining susceptibility to repolarization abnormalities could be due to $\mathrm{I}_{\mathrm{NaK}}$ 's role in maintaining intracellular $\mathrm{Na}^{+}$, the significant contribution of $\mathrm{I}_{\mathrm{NaK}}$ to repolarization reserve during $\mathrm{I}_{\mathrm{Kr}}$ block (Figure 6), or a combination of both effects. We therefore investigated the effects of intracellular $\mathrm{Na}^{+}$concentration and the electrogenic action of $\mathrm{I}_{\mathrm{NaK}}$ individually, to evaluate their contributions to the development of repolarization abnormalities. To investigate how intracellular $\mathrm{Na}^{+}$affected repolarization abnormality occurrence, we clamped its concentration to a physiologically normal value of $7 \mathrm{mM}$ (the baseline concentration in the ORd model), and to an overloaded value of $20 \mathrm{mM}$, which is within the range reported in heart failure (Pieske et al., 2002) and for acute ischemia. For the $20 \mathrm{mM}$ condition, we also clamped intracellular $\mathrm{K}^{+}$to $145 \mathrm{mM}$ to prevent rundown.

For intracellular $\mathrm{Na}^{+}$clamped at $7 \mathrm{mM}$, repolarization abnormalities occurred in 56 and $95 \%$ of models at 75 and $90 \%$ $\mathrm{I}_{\mathrm{Kr}}$ block respectively, close to the values for unclamped $\mathrm{Na}^{+}$. However, clamping intracellular $\mathrm{Na}^{+}$at $20 \mathrm{mM}$ and $\mathrm{K}^{+}$at 145 $\mathrm{mM}$ caused a reduction in repolarization abnormalities to 27 and
$46 \%$ of models at 75 and $90 \% \mathrm{I}_{\mathrm{Kr}}$ block respectively (Figure 7C). These results suggested that normal $\mathrm{Na}^{+}$concentration alone was not sufficient to prevent repolarization abnormalities, and that elevated intracellular $\mathrm{Na}^{+}$may make an important contribution to repolarization reserve and decrease occurrence of repolarization abnormalities by increasing the outward current through $\mathrm{I}_{\mathrm{NaK}}$.

To test whether the outward current provided by $\mathrm{I}_{\mathrm{NaK}}$ itself was an important contributor to repolarization reserve during $\mathrm{I}_{\mathrm{Kr}}$ block, we removed the electrogenic effects of $\mathrm{I}_{\mathrm{NaK}}$ on membrane potential, while still allowing ion transport to occur normally. Without the electrogenic contribution of $\mathrm{I}_{\mathrm{NaK}}$, repolarization abnormalities occurred in $93 \%$ of low $\mathrm{G}_{\mathrm{NaK}} \mathrm{HS}$ models following $75 \% \mathrm{I}_{\mathrm{Kr}}$ block, and in $100 \%$ of models following 90\% $\mathrm{I}_{\mathrm{Kr}}$ block (Figure 7C). This large increase in abnormalities when only the electrogenic component of $\mathrm{I}_{\mathrm{NaK}}$ was removed, even in models with a low baseline $\mathrm{G}_{\mathrm{NaK}}$, combined with the large relative magnitude of $\mathrm{I}_{\mathrm{NaK}}$ during repolarization shown in Figure 6, provides evidence supporting an important role for $\mathrm{I}_{\mathrm{NaK}}$ as a contributor to repolarization reserve in humans during $\mathrm{I}_{\mathrm{Kr}}$ block, over a wide range of different conductance profiles.

\section{Effects of Hypokalemia and Rapid Pacing on Repolarization}

Hypokalemia and $\mathrm{Ca}^{2+}$ loading are both known to increase the likelihood of afterdepolarization generation (Sato et al., 2010; Weiss et al., 2010; Despa and Bers, 2013). We investigated how much each phenomenon altered the incidence of repolarization abnormalities in the population of models under $I_{\mathrm{Kr}}$ block (Figure 8). Mild hypokalemia was simulated by reducing extracellular potassium from 5.4 to $4.0 \mathrm{mM}$ in each model. Each model in the population was simulated under these conditions at five levels of $\mathrm{I}_{\mathrm{Kr}}$ block: 0/25/50/75/90\%.

Reducing extracellular $\mathrm{K}^{+}$alone was not sufficient to generate repolarization abnormalities, but, combined with $\mathrm{I}_{\mathrm{Kr}}$ block it resulted in a small increase in the number of models that displayed abnormalities relative to control $\mathrm{K}^{+}$levels (Figure $\mathbf{8 B}$ ).

To investigate whether susceptibility was increased by $\mathrm{Ca}^{2+}$ loading, we used rapid pacing at $2.5 \mathrm{~Hz}$, which is known to cause $\mathrm{Ca}^{2+}$ loading (Maruyama et al., 2010), followed by a reduction in pacing rate to $1 \mathrm{~Hz}$ for the final two beats of each simulation, 

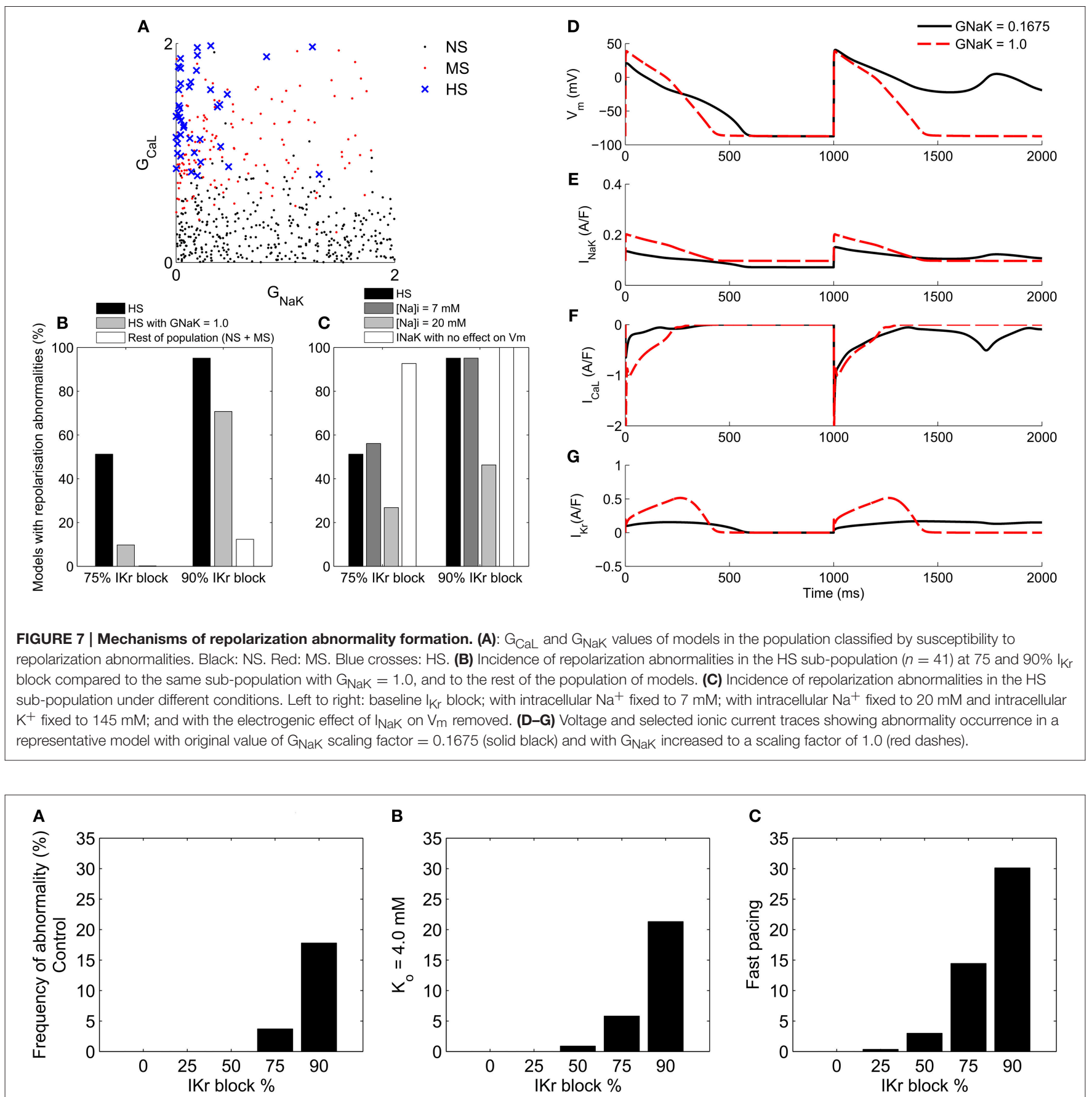

FIGURE 8 | Incidence of repolarization abnormalities in the population of models under different levels of $\mathrm{I}_{\mathrm{Kr}}$ block, following changes to extracellular potassium and intracellular calcium concentrations. (A) Control conditions ( $\left[\mathrm{K}^{+}\right]_{\mathrm{o}}=5.4 \mathrm{mM}, 1 \mathrm{~Hz}$ pacing). (B) Reduced extracellular potassium concentration $\left(\left[\mathrm{K}^{+}\right]_{\mathrm{O}}=4.0 \mathrm{mM}\right)$. (C) Rapid pacing $(2.5 \mathrm{~Hz})$ to increase $\mathrm{Ca}^{2+}$ loading, followed by sudden decrease to $1 \mathrm{~Hz}$.

to match the pacing rate to the other simulations in this study. This protocol resulted in $52 \%$ of models displaying an average increase in intracellular $\mathrm{Ca}^{2+}$ of $50 \%$ or more compared to pacing at $1 \mathrm{~Hz}$. The final two beats of each simulation showed no development of afterdepolarizations across the population under control conditions. However, pacing at $2.5 \mathrm{~Hz}$ lead to increased repolarization abnormality occurrence following $\mathrm{I}_{\mathrm{Kr}}$ block, as shown in Figure 8C. Afterdepolarization occurrence across the population increased from 4 to $14 \%$ of models at $75 \% \mathrm{I}_{\mathrm{Kr}}$ block, and from 18 to $30 \%$ at $90 \% \mathrm{I}_{\mathrm{Kr}}$ block. 


\section{DISCUSSION}

\section{Main Findings}

In this study, a population of human ventricular cardiomyocytes, calibrated using electrophysiological recordings to yield normal APs under control conditions, provides a quantitative understanding of the relative importance of ionic currents in the occurrence of repolarization abnormalities under ionic drug block. Our main findings include:

(1) $I_{K r}$ block was necessary for repolarization abnormalities to occur. No model in the population displayed repolarization abnormalities in any of the simulations in this study where $\mathrm{I}_{\mathrm{Kr}}$ was not blocked. This result is supported by the inclusion of simulations with simultaneous $90 \%$ block of the repolarizing $\mathrm{K}^{+}$currents $\mathrm{I}_{\mathrm{Ks}}$ and $\mathrm{I}_{\mathrm{K} 1}$, and the presence of models in our population with very low values of $\mathrm{G}_{\mathrm{Kr}}$ (Figure 3C). This finding highlights the particular importance of $\mathrm{I}_{\mathrm{Kr}}$ in human ventricular cardiomyocytes, and the unique role of $\mathrm{I}_{\mathrm{Kr}}$ block in destabilizing repolarization.

(2) Under $I_{\mathrm{Kr}}$ block, $\mathrm{I}_{\mathrm{NaK}}$ and also $\mathrm{I}_{\mathrm{CaL}}$ are the most important determinants of repolarization abnormality susceptibility. The importance of $\mathrm{G}_{\mathrm{NaK}}$ is a surprising finding, as the focus of investigation into the mechanisms of ventricular repolarization abnormalities has been on the roles of $\mathrm{K}^{+}$ and $\mathrm{Ca}^{2+}$ currents such as $\mathrm{I}_{\mathrm{Kr}}, \mathrm{I}_{\mathrm{Ks}}$, and $\mathrm{I}_{\mathrm{CaL}}$ (Roden and Abraham, 2011), and not on $\mathrm{I}_{\mathrm{NaK}}$. Reduced $\mathrm{I}_{\mathrm{NaK}}$ is common in disease such as ischaemia and heart failure (Schwinger et al., 1999; Fuller et al., 2003), is known to contribute to delayed afterdepolarization (DAD) formation (Rosen et al., 1973; Ferrier, 1976; Rosen, 1985), and can increase intracellular $\mathrm{Ca}^{2+}$ through $\mathrm{Na}^{+}$overload (Despa and Bers, 2013). However, $I_{\mathrm{NaK}}$ was not considered in previous studies to have a major role in generating repolarization abnormalities during the AP (e.g., EADs). Identification of high $\mathrm{G}_{C a L}$ was expected, based on previous experimental and computational studies highlighting the importance of $\mathrm{I}_{\mathrm{CaL}}$ for EAD generation (January and Riddle, 1989; Sims et al., 2008; Vandersickel et al., 2014).

(3) Our quantitative analysis shows that $I_{\mathrm{NaK}}$ is the main contributor to human repolarization current following $75 \%$ $\mathrm{I}_{\mathrm{Kr}}$ block, and the second largest contributor under control conditions, after $\mathrm{I}_{\mathrm{Kr}}$. Its contribution to repolarization reserve was larger than that of $\mathrm{I}_{\mathrm{Ks}}$ (Figure 6).

(4) $\mathrm{I}_{\mathrm{NaK}}$ 's low electrogenic contribution to repolarization reserve was a necessary component of the mechanism that caused repolarization abnormalities. $\mathrm{Na}^{+}$overload alone was not sufficient to explain how low $\mathrm{G}_{\mathrm{NaK}}$ caused repolarization abnormalities. Clamping $\mathrm{Na}^{+}$to a physiological level (7 $\mathrm{mM}$ ) had little effect on abnormality occurrence, while clamping $\mathrm{Na}^{+}$at an overloaded level $(20 \mathrm{mM})$ decreased abnormality occurrence. Removing the electrogenic effect of $\mathrm{I}_{\mathrm{NaK}}$ while retaining its ability to transport ions caused a large increase in repolarization abnormalities. Thus, repolarization abnormality occurrence was higher in low $\mathrm{G}_{\mathrm{NaK}}$ models because of changes in repolarizing current and ionic concentrations, and not $\mathrm{Na}^{+}$overload alone.

\section{Important Role of $I_{\mathrm{NaK}}$ in Human Repolarization Reserve and Drug-Induced Repolarization Abnormalities}

Unexpectedly, we found that $\mathrm{I}_{\mathrm{NaK}}$ was an important component of repolarization reserve, specifically, that it made the second largest overall contribution to repolarizing current after $\mathrm{I}_{\mathrm{Kr}}$. While $\mathrm{I}_{\mathrm{Kr}}$ inhibition and $\mathrm{I}_{\mathrm{CaL}}$ availability were sufficient for repolarization abnormalities to occur in the strongest drug block scenarios (i.e., 90\% $\mathrm{I}_{\mathrm{Kr}}$ block combined with block of either $\mathrm{I}_{\mathrm{Ks}}$ or $\mathrm{I}_{\mathrm{K} 1}$ ), when we analyzed the 41 models in the HS sub-population, we found that $\mathrm{G}_{\mathrm{NaK}}$ was less than $50 \%$ of its baseline value in 38/41 of these models (Figure 7A). Even in these models, $\mathrm{I}_{\mathrm{NaK}}$ was the largest contributor to repolarization current after $\mathrm{I}_{\mathrm{Kr}}$, and of greater magnitude than $\mathrm{I}_{\mathrm{Ks}}$ following $75 \% \mathrm{I}_{\mathrm{Kr}}$ block. A number of disease conditions are associated with reduced expression of the $\mathrm{Na}^{+} / \mathrm{K}^{+}$pump (Bueno-Orovio et al., 2014), including ischemia (Fuller et al., 2003), heart failure (Xu et al., 1996; Schwinger et al., 1999), and additional comorbidities such as diabetes (Bossuyt et al., 2005). The pump is also selectively blocked by cardiac glycosides, such as digoxin, digitoxin and digitalis (Suhail, 2010). Reports of the effects of reduced $\mathrm{G}_{\mathrm{NaK}}$ have focused on the role of the pump in maintaining $\mathrm{Na}^{+}$homeostasis, with elevation of intracellular $\mathrm{Na}^{+}$concentration linked to compromised $\mathrm{I}_{\mathrm{NaK}}$ (Wasserstrom and Aistrup, 2005). Our results identified $\mathrm{G}_{\mathrm{NaK}}$ as an important determinant of repolarization reserve across a wide range of conductance profiles, and suggest that reduction of repolarization reserve could be a further pro-arrhythmic effect of reduced $\mathrm{I}_{\mathrm{NaK}}$.

As well as being reduced in disease conditions, $\mathrm{I}_{\mathrm{NaK}}$ is inhibited by a range of drugs, including multichannel blockers and cardiac glycosides. For example, amiodarone, a commonly used anti-arrhythmic compound that affects multiple channels, also inhibits $\mathrm{I}_{\mathrm{NaK}}$ (Gray et al., 1998). Furthermore, there is evidence that cardiac glycosides can reduce trafficking of the hERG channel, which conducts $\mathrm{I}_{\mathrm{Kr}}$ in humans, and in particular, that digitoxin could cause a significant reduction in hERG trafficking at therapeutic concentrations (Wang et al., 2007). Another cardiac glycoside, digoxin, has been associated with increased risk of sudden cardiac death (Niemeijer et al., 2015). Therefore, there is a need for further experimental investigation to clarify the role of $\mathrm{I}_{\mathrm{NaK}}$ in ventricular repolarization, particularly following $\mathrm{I}_{\mathrm{Kr}}$ block. In addition, as the ORd model currently represents our most comprehensive quantitative model of human ventricular cardiomyocyte repolarization, experimental testing of this study's predictions will be important for determining if the ORd model accurately represents the role of $\mathrm{I}_{\mathrm{NaK}}$ in repolarization, or if the current model needs to be updated.

\section{AP Biomarkers Could Not Distinguish Normal and Abnormal Models}

Within the population of models a wide variety of conductance profiles produced viable APs (Figure 3A), far from the original conductances of the baseline ORd model. This is consistent 
with results from previous studies showing the robustness of APs to changes in ionic conductances (Marder and Taylor, 2011; Sarkar and Sobie, 2011; Sánchez et al., 2014; Passini et al., 2016; Zhou et al., 2016). Therefore, all models in the population displayed normal APs with important AP biomarkers within the experimental physiological range. However, across the population there were large differences in models' responses to current block. Even under high levels of $\mathrm{I}_{\mathrm{Kr}}$ block, most models did not develop repolarization abnormalities (Figures 5A-C), but almost all models did exhibit substantial APD prolongation (Figure S3B). Therefore, while strong $\mathrm{I}_{\mathrm{Kr}}$ block alone is sufficient to cause AP prolongation, it is not sufficient to cause repolarization abnormalities, and also requires an additional mechanism, such as the combination of high $\mathrm{I}_{\mathrm{CaL}}$ and low $\mathrm{I}_{\mathrm{NaK}}$. Further, through a logistic regression model, we found that different levels of susceptibility to drug-induced repolarization abnormalities could not be identified prior to current block using standard AP biomarkers and control conditions simulations alone. The logistic regression model could, on average, only correctly assign $61 \%$ of the HS models to the HS category. However, combining classification techniques from machine learning and recordings from additional experimental conditions could potentially discover combinations of key features that are more predictive of response to drug block.

\section{Future Directions}

In this study, we focused on variability of channel densities, and therefore sarcolemmal conductances, as an important source of variability because of the wide array of biological phenomena known to alter ion channel expression and trafficking, and because conductance alteration through block is the primary mechanism through which many pharmaceutical compounds act on the heart. We have shown that variation in sarcolemmal conductances alone is sufficient to produce drug-induced repolarization abnormalities in models with normal control APs and APDs. However, as ion channel kinetics can vary significantly between individuals, e.g., through genetic mutations (Marban, 2002), future studies could investigate how variation in channel kinetics interacts with conductance variability, e.g., for inherited channelopathies associated with long QT syndrome. For studies investigating phenomena that are known to increase the current through particular channels (e.g., beta-adrenergic stimulation), increasing the range of sampled conductance values for those particular currents could also be useful.

The experimental recordings used in this study, and therefore the sources of AP biomarker variability used to calibrate the population of models, were recorded from endocardial tissue in the right ventricle. Electrophysiological properties vary intramurally and between left and right ventricles (Bueno-Orovio et al., 2012), and these additional sources of electrophysiological variability were not considered in this study. However, we believe the wide ranges of AP biomarker values and conductance profiles considered here mitigate this limitation, particularly relative to using a single model of ventricular electrophysiology.
Although this was not the focus of our investigations, reduced $\mathrm{I}_{\mathrm{NaK}}$ has been linked to DAD occurrence (Rosen et al., 1973; Rosen, 1985; Despa and Bers, 2013). DADs were not observed in any model in the population using the stimulation protocols in our simulations, although we did not specifically design simulation protocols to generate them. Therefore, specific simulation protocols and possibly alterations in model structure, particularly in the calcium sub-system, may be required for these investigations.

Even under heavy $\mathrm{I}_{\mathrm{Kr}}$ block, only a minority of models in the population displayed abnormalities, and these models occupied a limited parameter regime. It is therefore likely that EAD formation in vivo requires the combined action of multiple destabilizing factors, as in healthy tissue electrotonic coupling suppresses repolarization abnormalities unless they occur simultaneously in a large number of coupled cells (Xie et al., 2010). Electrotonic coupling would also likely prevent the complete repolarization failure that occurred in some models under high $\mathrm{I}_{\mathrm{Kr}}$ block from occurring in vivo. However, in diseased or damaged tissue, reduced cellular coupling, combined with increased structural heterogeneity could potentially overcome electrotonic coupling (Shaw and Rudy, 1997; Xie et al., 2010), or even cause electrotonic current to become a generative mechanism for EAD development (Dutta et al., 2016). This tissue-level destabilization could increase the range of ionic profiles that are vulnerable to developing repolarization abnormalities and reduce the level of drug block required to initiate them. Therefore, understanding how tissue heterogeneity interacts with variability in conductances and drug block to influence repolarization abnormality formation is an important topic for future investigations.

\section{AUTHOR CONTRIBUTIONS}

Conceived and designed study: $\mathrm{OB}, \mathrm{AB}$, and BR. Acquired experimental recordings: $\mathrm{LV}$ and $\mathrm{AV}$. Performed simulations and analyzed data: $O B$. Drafted manuscript: $O B, A B$, and BR. All authors contributed to critical revision of the manuscript and approved the final version to be published.

\section{FUNDING}

This work was supported by an Engineering and Physical Sciences Research Council-funded Systems Biology Doctoral Training Centre studentship and Doctoral Prize (OB), the 2014 National Centre for the 3Rs Prize (OB) and a Welcome Trust Senior Research Fellowship in Basic Biomedical Science to BR $(100246 / \mathrm{Z} / 12 / \mathrm{Z})(\mathrm{AB}, \mathrm{LV}, \mathrm{AV}$, and BR).

\section{SUPPLEMENTARY MATERIAL}

The Supplementary Material for this article can be found online at: http://journal.frontiersin.org/article/10.3389/fphys. 2017.00278/full\#supplementary-material 


\section{REFERENCES}

Borg, T. K., and Terracio, L. (1990). "Attachment substrates for heart muscle cells," in Cell Culture Techniques in Heart and Vessel Research, ed H. M. Piper (Berlin; Heidelberg: Springer), 99-107.

Bossuyt, J., Ai, X., Moorman, J. R., Pogwizd, S. M., and Bers, D. M. (2005). Expression and phosphorylation of the Na-pump regulatory subunit phospholemman in heart failure. Circ. Res. 97, 558-565. doi: 10.1161/01.RES.0000181172.27931.c3

Britton, O. J., Bueno-Orovio, A., Van Ammel, K., Lu, H. R., Towart, R., Gallacher, D. J., et al. (2013). Experimentally calibrated population of models predicts and explains intersubject variability in cardiac cellular electrophysiology. Proc. Natl. Acad. Sci. U.S.A. 110, E2098-E2105. doi: 10.1073/pnas.13043 82110

Bueno-Orovio, A., Hanson, B. M., Gill, J. S., Taggart, P., and Rodriguez, B. (2012). In vivo human left-to-right ventricular differences in rate adaptation transiently increase pro-arrhythmic risk following rate acceleration. PLOS ONE 7:e52234. doi: 10.1371/journal.pone.0052234

Bueno-Orovio, A., Sanchez, C., Pueyo, E., and Rodriguez, B. (2014). Na/K pump regulation of cardiac repolarization: insights from a systems biology approach. Pflugers Arch. 466, 183-193. doi: 10.1007/s00424-013-1293-1

Despa, S., and Bers, D. M. (2013). $\mathrm{Na}^{+}$transport in the normal and failing heart - remember the balance. J. Mol. Cell. Cardiol. 61, 2-10. doi: 10.1016/j.yjmcc.2013.04.011

Dutta, S., Mincholé, A., Zacur, E., Quinn, T. A., Taggart, P., and Rodriguez, B. (2016). Early afterdepolarizations promote transmural reentry in ischemic human ventricles with reduced repolarization reserve. Prog. Biophys. Mol. Biol. 120, 236-248. doi: 10.1016/j.pbiomolbio.2016.01.008

Ferrier, G. R. (1976). The effects of tension on acetylstrophanthidin-induced transient depolarizations and aftercontractions in canine myocardial and Purkinje tissues. Circ. Res. 38, 156-162. doi: 10.1161/01.RES.38. 3.156

Fuller, W., Parmar, V., Eaton, P., Bell, J. R., and Shattock, M. J. (2003). Cardiac ischemia causes inhibition of the $\mathrm{Na} / \mathrm{K}$ ATPase by a labile cytosolic compound whose production is linked to oxidant stress. Cardiovasc. Res. 57, 1044-1051. doi: 10.1016/S0008-6363(02)00810-6

Gray, D. F., Mihailidou, A. S., Hansen, P. S., Buhagiar, K. A., Bewick, N. L., Rasmussen, H. H., et al. (1998). Amiodarone inhibits the $\mathrm{Na}^{+}-\mathrm{K}^{+}$pump in rabbit cardiac myocytes after acute and chronic treatment. J. Pharm. Exp. Ther. $284,75-82$.

January, C. T., and Riddle, J. M. (1989). Early afterdepolarizations: mechanism of induction and block. A role for L-type $\mathrm{Ca}^{2+}$ current. Circ. Res. 64, 977-990. doi: 10.1161/01.RES.64.5.977

Jeyaraj, D., Haldar, S. M., Wan, X., McCauley, M. D., Ripperger, J. A., Hu, K., et al. (2012). Circadian rhythms govern cardiac repolarization and arrhythmogenesis. Nature 483, 96-99. doi: 10.1038/nature10852

Jost, N., Virag, L., Bitay, M., Takacs, J., Lengyel, C., Biliczki, P., et al. (2005). Restricting excessive cardiac action potential and QT prolongation a vital role for iks in human ventricular muscle. Circulation 112, 1392-1399. doi: 10.1161/CIRCULATIONAHA.105.550111

Jost, N., Virág, L., Comtois, P., Ördög, B., Szuts, V., Seprényi, G., et al. (2013). Ionic mechanisms limiting cardiacrepolarization reserve in humans compared to dogs. J. Physiol. 591, 4189-4206. doi: 10.1113/jphysiol.2013.261198

Kim, G. H. (2013). MicroRNA regulation of cardiac conduction and arrhythmias. Transl. Res. 161, 381-392. doi: 10.1016/j.trsl.2012. 12.004

Kramer, J., Obejero-Paz, C. A., Myatt, G., Kuryshev, Y. A., Bruening-Wright, A., Verducci, J. S., et al. (2013). MICE models: superior to the HERG model in predicting Torsade de Pointes. Sci. Rep. 1, 3. doi: 10.1038/srep 02100

Marban, E. (2002). Cardiac channelopathies. Nature 415, 213-218. doi: $10.1038 / 415213 a$

Marder, E., and Taylor, A. L. (2011). Multiple models to capture the variability in biological neurons and networks. Nat. Neurosci. 14, 133-138. doi: $10.1038 / \mathrm{nn} .2735$

Maruyama, M., Joung, B., Tang, L., Shinohara, T., On, Y. K., Han, S., et al. (2010). Diastolic intracellular calcium membrane voltage coupling gain and postshock arrhythmias: role of purkinje fibers and triggered activity. Circ. Res. 106, 399-408. doi: 10.1161/CIRCRESAHA.109.211292

McKay, M. D., Beckman, R. J., and Conover, W. J. (1979). A comparison of three methods for selecting values of input variables in the analysis of output from a computer code. Technometrics 21, 239-245. doi: 10.1080/00401706.1979.10489755

Michael, G., Xiao, L., Qi, X. Y., Dobrev, D., and Nattel, S. (2009). Remodelling of cardiac repolarization: how homeostatic responses can lead to arrhythmogenesis. Cardiol. Res. 81, 491-499. doi: 10.1093/cvr/cvn266

Nass, R. D., Aiba, T., Tomaselli, G. F., and Akar, F. G. (2008). Mechanisms of disease: ion channel remodeling in the failing ventricle. Nat. Clin. Pract. Card. 5, 196-207. doi: 10.1038/ncpcardio1130

Nattel, S., Frelin, Y., Gaborit, N., Louault, C., and Demolombe, S. (2010). Ion-channel mRNA-expression profiling: insights into cardiac remodeling and arrhythmic substrates. J. Mol. Cell. Cardiol. 48, 96-105. doi: 10.1016/j.yjmcc.2009.07.016

Nattel, S., Maguy, A., Le Bouter, S., and Yeh, Y. H. (2007). Arrhythmogenic ion-channel remodeling in the heart: heart failure, myocardial infarction, and atrial fibrillation. Physiol. Rev. 87, 425-456. doi: 10.1152/physrev.0001 4.2006

Niemeijer, M. N., van den Berg, M. E., Deckers, J. W., Aarnoudse, A. L., Hofman, A., Franco, O. H., et al. (2015). ABCB1 gene variants, digoxin and risk of sudden cardiac death in a general population. Heart 101, 1973-1979. doi: 10.1136/heartjnl-2014-307419

Odening, K. E., and Koren, G. (2014). How do sex hormones modify arrhythmogenesis in long QT syndrome? Sex hormone effects on arrhythmogenic substrate and triggered activity. Heart Rhythm 11, 2107-2115. doi: 10.1016/j.hrthm.2014.06.023

O'Hara, T., Virag, L., Varro, A., and Rudy, Y. (2011). Simulation of the undiseased human cardiac ventricular action potential: model formulation and experimental validation. PLoS Comput. Biol. 7:e1002061. doi: 10.1371/journal.pcbi.1002061

Passini, E., Minchole, A., Coppini, R., Cerbai, E., Rodriguez, B., Severi, S., et al. (2016). Mechanisms of pro-arrhythmic abnormalities in ventricular repolarisation and anti-arrhythmic therapies in human hypertrophic cardiomyopathy. J. Mol. Cell. Cardiol. 96, 72-81. doi: 10.1016/j.yjmcc.2015.09.003

Pieske, B., Maier, L. S., Piacentino, V., Weisser, J., Hasenfuss, G., and Houser, S. (2002). Rate dependence of $\left[\mathrm{Na}^{+}\right]_{i}$ and contractility in nonfailing and failing human myocardium. Circulation 106, 447-453. doi: 10.1161/01.CIR.0000023042.50192.F4

Polak, S., Winiowska, B., and Brandys, J. (2009). Collation, assessment and analysis of literature in vitro data on hERG receptor blocking potency for subsequent modeling of drugs' cardiotoxic properties. J. Appl. Toxicol. 29, 183-206. doi: 10.1002/jat.1395

Qi, X. Y., Yeh, Y. H., Xiao, L., Burstein, B., Maguy, A., Chartier, D., et al. (2008). Cellular signaling underlying atrial tachycardia remodeling of L-type calcium current. Circ. Res. 103, 845-854. doi: 10.1161/CIRCRESAHA.108.1 75463

Roden, D. M. (1998). Taking the idio out of idiosyncratic: predicting torsades de pointes. Pacing Clin. Electrophysiol. 21, 1029-1034. doi: 10.1111/j.1540-8159.1998.tb00148.x

Roden, D. M., and Abraham, R. L. (2011). Refining repolarization reserve. Heart Rhythm 8, 1756. doi: 10.1016/j.hrthm.2011.06.024

Rosen, M. R. (1985). Cellular electrophysiology of digitalis toxicity. J. Am. Coll. Cardiol. 5, 22A-34A. doi: 10.1016/S0735-1097(85)80460-5

Rosen, M. R., Gelband, H., Merker, C., and Hoffman, B. F. (1973). Mechanisms of digitalis toxicity. Circulation 47, 681-689. doi: 10.1161/01.CIR. 47.4.681

Sánchez, C., Bueno-Orovio, A., Wettwer, E., Loose, S., Simon, J., Ravens, U., et al. (2014). Inter-subject variability in human atrial action potential in sinus rhythm versus chronic atrial fibrillation. PLOS ONE 9:e105897. doi: 10.1371/journal.pone.0105897

Sarkar, A. X., and Sobie, E. A. (2011). Quantification of repolarization reserve to understand interpatient variability in the response to proarrhythmic drugs: a computational analysis. Heart Rhythm 8, 1749-1755. doi: $10.1016 /$ j.hrthm.2011.05.023 
Sato, D., Xie, L. H., Nguyen, T. P., Weiss, J. N., and Qu, Z. (2010). Irregularly appearing early afterdepolarizations in cardiac myocytes: random fluctuations or dynamical chaos? Biophys. J. 99, 765-773. doi: 10.1016/j.bpj.2010.05.019

Schwinger, R. H., Wang, J., Frank, K., Müller-Ehmsen, J., Brixius, K., McDonough, A. A., et al. (1999). Reduced sodium pump $\alpha_{1}, \alpha_{3}$, and $\beta_{1}$-isoform protein levels and $\mathrm{Na}^{+}, \mathrm{K}^{+}$-ATPase activity but unchanged $\mathrm{Na}^{+}-\mathrm{Ca}^{2+}$ exchanger protein levels in human heart failure. Circulation 27, 2105-2112. doi: 10.1161/01.CIR.99.16.2105

Shattock, M. J., Ottolia, M., Bers, D. M., Blaustein, M. P., Boguslavskyi, A., Bossuyt, J., et al. (2015). $\mathrm{Na}^{+} / \mathrm{Ca}^{2+}$ exchange and $\mathrm{Na}^{+} / \mathrm{K}^{+}$-ATPase in the heart. $J$. Physiol. 593, 1361-1382. doi: 10.1113/jphysiol.2014.282319

Shaw, R. M., and Rudy, Y. (1997). Ionic mechanisms of propagation in cardiac tissue roles of the sodium and 1-type calcium currents during reduced excitability and decreased gap junction coupling. Circ. Res. 1, 727-741. doi: 10.1161/01.RES.81.5.727

Sims, C., Reisenweber, S., Viswanathan, P. C., Choi, B. R., Walker, W. H., and Salama, G. (2008). Sex, age, and regional differences in L-type calcium current are important determinants of arrhythmia phenotype in rabbit hearts with drug-induced long QT type 2. Circ. Res. 102, e86-e100. doi: 10.1161/CIRCRESAHA.108.173740

Suhail, M. (2010). $\mathrm{Na}^{+}, \mathrm{K}^{+}$-ATPase: ubiquitous multifunctional transmembrane protein and its relevance to various pathophysiological conditions. J. Clin. Med. Res. 2, 1-17. doi: 10.4021/jocmr2010.02.263w

Vandersickel, N., Kazbanov, I. V., Nuitermans, A., Weise, L. D., Pandit, R., and Panfilov, A. V. (2014). Study of early afterdepolarizations in a model for human ventricular tissue. PLoS ONE 9:e84595. doi: 10.1371/journal.pone.0084595

Varró, A., Takács, J., Németh, M., Hála, O., Virág, L., Iost, N., et al. (2001). Electrophysiological effects of dronedarone (SR 33589), a noniodinated amiodarone derivative in the canine heart: comparison with amiodarone. Brit. J. Pharmacol. 133, 625-634. doi: 10.1038/sj.bjp.0704106

Varro, A., and Baczko, I. (2011). Cardiac ventricular repolarization reserve: a principle for understanding drug-related proarrhythmic risk. Brit. J. Pharmacol. 164, 14-36. doi: 10.1111/j.1476-5381.2011.01367.x

Wang, L., Wible, B. A., Wan, X., and Ficker, E. (2007). Cardiac glycosides as novel inhibitors of human ether-ago-go-related gene channel trafficking. J. Pharm. Exp. Ther. 320, 525-534. doi: 10.1124/jpet.106.113043
Wasserstrom, J. A., and Aistrup, G. L. (2005). Digitalis: new actions for an old drug. Am. J. Physiol. Heart Circ. Physiol. 289, H1781-H1793. doi: 10.1152/ajpheart.00707.2004

Weiss, J. N., Garfinkel, A., Karagueuzian, H. S., Chen, P. S., and Qu, Z. (2010). Early afterdepolarizations and cardiac arrhythmias. Heart Rhythm 7, 1891-1899. doi: 10.1016/j.hrthm.2010.09.017

Xiao, L., Xiao, J., Luo, X., Lin, H., Wang, Z., and Nattel, S. (2008). Feedback remodeling of cardiac potassium current expression a novel potential mechanism for control of repolarization reserve. Circulation 118, 983-992. doi: 10.1161/CIRCULATIONAHA.107.758672

Xie, Y., Sato, D., Garfinkel, A., Qu, Z., and Weiss, J. N. (2010). So little source, so much sink: requirements for afterdepolarizations to propagate in tissue. Biophys. J. 99, 1408-1415. doi: 10.1016/j.bpj.2010.06.042

Xu, J., Zaim, S., and Pelleg, A. (1996). Effects of pinacidil, verapamil, and heart rate on afterdepolarizations in the guinea-pig heart in vivo. Heart Vessels 11, 289-302. doi: 10.1007/BF01747188

Zhang, S., Zhou, Z., Gong, Q., Makielski, J. C., and January, C. T. (1999). Mechanism of block and identification of the verapamil binding domain to HERG potassium channels. Circ. Res. 84, 989-998. doi: 10.1161/01.RES.84.9.989

Zhou, X., Bueno-Orovio, A., Orini, M., Hanson, B., Hayward, M., Taggart, P., et al. (2016). In vivo and in silico investigation into mechanisms of frequency dependence of repolarization alternans in human ventricular cardiomyocytes. Circ. Res. 118, 266-278. doi: 10.1161/CIRCRESAHA.115.307836

Conflict of Interest Statement: The authors declare that the research was conducted in the absence of any commercial or financial relationships that could be construed as a potential conflict of interest.

Copyright (c) 2017 Britton, Bueno-Orovio, Virág, Varró and Rodriguez. This is an open-access article distributed under the terms of the Creative Commons Attribution License (CC BY). The use, distribution or reproduction in other forums is permitted, provided the original author(s) or licensor are credited and that the original publication in this journal is cited, in accordance with accepted academic practice. No use, distribution or reproduction is permitted which does not comply with these terms. 